\title{
Desenvolvimento de um ambiente virtual para o ensino da medicina por uma equipe multidisciplinar: fatores que influenciam a análise do problema educativo ${ }^{*}$
}

Paula Ramos ${ }^{1}$

Miriam Struchiner ${ }^{2}$

RAMOS, P. STRUCHINER, M. Development of a virtual environment for medical education by a multidisciplinary team: factors that influence the analysis on the educational problem. Interface - Comunic., Saude, Educ., v.15, n.36, p.227-42, jan./mar. 2011.

This study investigated the analysis phase of the educational problem in the research and development process for a virtual environment for teaching medicine, guided by the design-based research methodology. A multidisciplinary team composed of educational technology and healthcare researchers discussed the problem of technicist training and the need to emphasize patients' subjective experiences of illness and treatment as a way of including ethical values in the training. Based on content analysis of the transcripts of the team meetings, the factors that influenced the negotiation process for defining the educational problem, the aims of the virtual environment and the guiding theory for its development were discussed. It was concluded that in analyzing complex problems such as healthcare, it is essential to take into account epistemological beliefs (about healthcare education, healthcare, and educational technology) and teachers' knowledge (from experiences and academic disciplines).

Keywords: Design-based research. Virtual learning environment. Medical training. Epistemological beliefs. Teachers' knowledge.
Este estudo investigou a fase de análise do problema educativo no processo de pesquisa e desenvolvimento de um ambiente virtual para ensino de Medicina, apoiado na metodologia da Pesquisa Baseada em Design. A equipe multidisciplinar, composta por pesquisadores de tecnologia educacional e saúde, discutiu o problema da formação tecnicista e a necessidade de enfatizar experiências subjetivas dos pacientes sobre o adoecimento e tratamento, como forma de incluir valores éticos na formação. Com base na análise de conteúdo das transcrições das reuniões da equipe, discutiram-se os aspectos que influenciaram a negociação para definição do problema educativo, dos objetivos do ambiente e da teoria norteadora do seu desenvolvimento. Concluiu-se que, na análise de problemas complexos, como os da saúde, é fundamental a integração das crenças epistemológicas - sobre formação em saúde, saúde e tecnologia educacional - e dos saberes docentes - experienciais e disciplinares.

Palavras-chave: Pesquisa baseada em design. Ambiente virtual de aprendizagem. Formação médica. Crenças epistemológicas. Saberes docentes.
"Texto elaborado com base em Ramos (2010);

projeto de pesquisa financiado pela Faperj (APQ1), e aprovado no Comitê de Ética do Hospital Universitário Clementino Fraga Filho.

${ }^{1}$ Núcleo de Tecnologia Educacional para a Saúde (NUTES), Universidade Federal do Rio de Janeiro (UFRJ). Av. Carlos Chagas Filho, Edifício do Centro de Ciências da Saúde, bloco A, sala 12. Ilha do Fundão, Rio de Janeiro, RJ, Brasil. 21.949-902. Apoio Capes. paularamos2612@ yahoo.com.br ${ }^{2}$ NUTES, UFRJ. Apoio CNPq. 


\section{Introdução}

O trabalho clínico implica, necessariamente, escolha e tomada de decisão (Serpa Jr.,1999). Para diminuir a incerteza desse processo, especialistas lançam mão de diferentes recursos, tais como: exames clínicos, bibliografia especializada e avaliação de evidências. Em geral, as decisões se baseiam na dimensão sintomatológica dos quadros clínicos, em que os aspectos subjetivos relacionados às experiências de adoecimento dos pacientes não são considerados (Serpa Jr., 1999).

Como abordagem alternativa, a "medicina baseada em narrativas" propõe a valorização da dimensão subjetiva e experiencial envolvida no adoecimento e tratamento dos pacientes, contemplando o caráter "complexo, multidimensional e fundado na experiência individual" da prática médica (Greenhalgh, 1996, p.959). Essa abordagem exige mudanças na formação tradicional dos profissionais de saúde, baseada em modelos tecnicistas, e impõe o desafio de valorizar outras dimensões do processo saúde-doença não inscritas no âmbito biológico, para formar profissionais com competências que Ihes permitam humanizar a relação médico-paciente (Ceccim, Feuerwerker, 2004).

Planejar e integrar intervenções educacionais que promovam estas mudanças envolvem atividades onde interagem não apenas conceitos e métodos, mas a cultura que permeia tanto a prática da clínica como a educação de profissionais. Portanto, uma das questões centrais consiste em aprofundar o conhecimento sobre os problemas educativos. Analisar esses problemas e compreendê-los com base nas especificidades dos contextos e de teorias de aprendizagem são elementos-chave de pesquisas que pretendem assumir relevância social, contribuindo para a melhoria das práticas educativas e para a construção de conhecimentos sobre o processo de ensino-aprendizagem (Reeves, Herrington, Oliver, 2005). Isto porque a análise do problema educativo constitui o ponto de partida para o planejamento, desenvolvimento, implementação e avaliação de intervenções em contextos naturais de ensino e aprendizagem (Mion, Angotti, 2005). Esta é a questão central da Metodologia de Pesquisa Baseada em Design ${ }^{3}$ (PBD), uma abordagem teórico-metodológica que vem se consolidando no campo da educação, com base em críticas a modelos tradicionais que promovem a ruptura entre pesquisa e práticas educacionais (Wang, Hannafin, 2005; Design-Based Research Collective DBRC, 2003).

Em linhas gerais, a PBD se caracteriza: pelo foco em problemas educativos complexos situados nos contextos de ensino-aprendizagem; pela colaboração intensa entre pesquisadores e sujeitos envolvidos nas práticas pedagógicas professores e alunos; pelo desenvolvimento de experiências/intervenções educativas para contribuir na solução desses problemas; pela integração de teorias educacionais, tanto para compreender os problemas quanto para desenvolver intervenções, e pela realização de um processo cíclico de análise, desenvolvimento, avaliação e redesign das intervenções, em que cada ciclo constitui uma oportunidade de pesquisa tanto sobre o próprio desenvolvimento quanto sobre as experiências de ensino-aprendizagem proporcionadas pela intervenção (Wang, Hannafin, 2005).

Nessa perspectiva, as questões de pesquisa surgem dos problemas e necessidades encontrados nas práticas educativas e identificados pelos sujeitos nelas envolvidos. Kozma (2000) aponta a importância da parceria entre pesquisadores e sujeitos das práticas para "compreender profundamente suas necessidades, objetivos e problemas" (Kozma, 2000, p.13). Assim, o desenvolvimento de intervenções pedagógicas é baseado na tomada de decisão
${ }^{3} \mathrm{O}$ nome original é Design-Based Research ou Design Experiments (Brown, 1992; Collins, 1992). A palavra

"design" assume o sentido de desenvolvimento. 
${ }^{4} \mathrm{O}$ "Projeto Vivências: espaços virtuais na aprendizagem das dimensões experiencial e narrativa dos processos de adoecimento" (Struchiner, 2008) é apoiado pela FAPERJ desde agosto de 2008. negociada na equipe. Na PBD, compreender esse processo, tornando-o explícito, é uma oportunidade de construção de conhecimento sobre o próprio desenvolvimento de intervenções pedagógicas, onde se incluem aquelas mediadas pelas tecnologias de informação e comunicação (TICS) (Edelson, 2002).

Estudos que buscam compreender o processo de análise do problema educativo oferecem subsídios para aprofundar a reflexão sobre a natureza desses problemas em diferentes áreas do conhecimento, apontando questões críticas e possíveis soluções.

Este trabalho relata a negociação de uma equipe multidisciplinar, formada por professores de um curso de Medicina e pesquisadores em Tecnologia Educacional em Saúde, durante a fase de análise do problema educativo, em uma atividade de pesquisa baseada em design de um ambiente virtual de aprendizagem - o Ambiente "Vivências"4. O objetivo do "Vivências" é explorar os recursos da internet para oferecer, a alunos do curso de Medicina, novos espaços para vivenciarem a experiência de adoecimento e tratamento, a partir de narrativas dos pacientes. Nesse estudo, identificamos e analisamos os aspectos que influenciaram a negociação da equipe na definição do problema educativo, dos objetivos do ambiente e da teoria norteadora de seu desenvolvimento.

\section{Análise do problema educativo com base na Pesquisa Baseada em Design (PBD)}

Jonassen (2000, p.65) considera que um problema é "uma entidade desconhecida resultante de qualquer situação em que uma pessoa busca satisfazer uma necessidade ou atingir um objetivo". O autor ressalta que problemas existem na medida em que são "necessidades sentidas", que motivam as pessoas a buscarem soluções para eliminar discrepâncias. Ou seja, um problema é definido por uma lacuna entre o que se percebe como ideal e o vivenciado.

Em relação aos problemas educativos, Mion e Angotti (2005) sugerem uma aproximação com a definição de "preocupação temática" que, segundo os autores, constitui o ponto de partida da pesquisa educacional e consiste em problematizar, dialogicamente, com os envolvidos, a situação-problema que está sendo vivida e se deseja transformar (Mion, Angotti, 2005). Sobre isso, Angulo (1990) considera que, refletindo sobre suas ações, os professores têm a possibilidade de analisar criticamente sua realidade e formulá-la como problema. Para o autor, os questionamentos podem envolver: a prática educativa, com foco em alguma "situação-limite" educacional; a compreensão que os participantes têm dessa prática, relacionada ao conhecimento alternativo, intuitivo ou do senso comum, e a percepção que têm da situação social em que atuam. Ressalta, ainda, que essas formulações não podem ser consideradas como dados objetivos, visto que são ideologizadas e dependentes da percepção interpretativa do professor e de suas concepções de educação e ensino-aprendizagem (Angulo, 1990).

Jonassen (1997) caracteriza os problemas educativos como complexos e "malestruturados" (ill-structured), uma vez que estes problemas não pressupõem uma solução única, correta ou melhor, mas uma série de possíveis alternativas de acordo com o contexto e a situação em que se inserem. Para Jonassen (1997), esses problemas representam dilemas específicos e inseparáveis do contexto em que se inserem, exigindo a avaliação de diferentes aspectos (por exemplo, problemas éticos e ambientais). Segundo Jonassen (2000), sobretudo em problemas mal-estruturados, as crenças epistemológicas influenciam significativamente sua abordagem. O autor define essas crenças como concepções 
individuais sobre ensino e aprendizagem e ressalta que, embora a relação entre crenças epistemológicas e resolução de problemas seja evidente, esta não tem sido pesquisada e merece, portanto, maior atenção.

Outro fator que Jonassen (2000) aponta como relevante é o conhecimento do campo. Refere-se ao repertório de conhecimentos que os indivíduos constroem sobre as áreas em que atuam e são referências para compreenderem o problema e desenvolverem soluções integradamente às especificidades do contexto. No caso dos professores, os conhecimentos do campo se aproximam do conceito de saberes docentes, que são aqueles construídos pelos professores ao longo da vida profissional, incluindo saberes adquiridos na formação, constituindo:

conhecimentos teóricos (saberes disciplinares) e aqueles construídos no exercício de suas funções e prática profissional (saberes experienciais) (Tardif, 2002). Alguns autores apontam a existência de crenças epistemológicas gerais e específicas, relacionadas ao campo de atuação dos professores (Olafson, Schraw, 2006).

No planejamento de intervenções pedagógicas, que integram sujeitos com diferentes expertises, a análise do problema educativo exige negociação dos diferentes saberes e crenças. Assim, o papel dos pesquisadores é situar os problemas educativos no contexto social em que se inserem, buscando relacionar as necessidades sentidas, os saberes e as crenças envolvidas por meio de revisão da literatura, estudos de caso e teorias de aprendizagem (Van den Akker, 1999). Segundo Juuti e Lavonen (2006), essa análise teórica do problema é necessária para definir teorias de aprendizagem (teorias norteadoras) que, além de fundamentarem a compreensão dos problemas educativos, orientam a modelagem, construção e pesquisa de inovações no contexto educacional. Assim, essa fase compreende a articulação de conhecimentos práticos e teóricos para identificação do problema, a definição dos objetivos e da teoria norteadora.

\section{Materiais e métodos}

O Projeto Vivências tem como objetivo valorizar as narrativas dos pacientes como um elemento-chave na formação dos profissionais de saúde, possibilitando aumentar a tolerância à incerteza da prática clínica e propiciar a atenção empática a pacientes (Hunter, Charon, Coulehan, 1995). Estratégias pedagógicas mediadas pela internet, especificamente, os recursos de interação e comunicação da Web $2.0^{5}$, são possíveis caminhos a serem explorados para oferecer, aos alunos, novos espaços para experimentarem e vivenciarem o fenômeno do adoecimento e tratamento em sua diversidade e complexidade (Struchiner, 2008). Especialmente, se considerarmos a carga horária minimizada pelo excesso de disciplinas e a impossibilidade da presença de grande número de pacientes com experiências diferenciadas.

O Ambiente Vivências vem sendo desenvolvido por uma equipe multidisciplinar, formada por: pesquisadores de tecnologia educacional (TE) $(n=2)$, professores de medicina $(n=3)$, web designer $(n=1)$, alunos de doutorado e mestrado em TE $(n=2)$, e alunos de iniciação científica de biologia $(n=1)$, informática $(n=2)$ e medicina $(n=2)$. Seguindo a dinâmica de trabalho orientada pela equipe de $T E$, a análise do problema educativo ocorreu em reuniões semanais com os participantes, para que todas as decisões fossem tomadas coletivamente. Nessas reuniões, os professores da saúde e os pesquisadores em tecnologia educacional discutiam os problemas e desafios da área do ensino da saúde, especificamente relacionados à desvalorização da dimensão subjetiva sobre o adoecimento e tratamento do paciente na formação em saúde. A discussão e

\author{
${ }^{5}$ A Web 2.0 é a segunda \\ geração de serviços na \\ rede, caracterizada por \\ ampliar as formas de \\ produção cooperada e \\ compartilhamento de \\ informações online \\ (Primo, 2006).
}


compreensão desse problema ofereceu subsídios para a equipe planejar em conjunto o ambiente virtual de aprendizagem "Vivências".

Para analisar as negociações e formulações do grupo ao longo do percurso, as reuniões foram observadas e as discussões gravadas em áudio e, posteriormente, transcritas. Foram analisadas três reuniões referentes à fase de análise do problema, totalizando cerca de quatro horas de gravação.

Como os dados para a realização desta pesquisa eram as interações entre os participantes, foi realizado um estudo de natureza qualitativa com base no método de análise de conteúdo (Minayo, 1994; Bardin, 1977). Optou-se pela técnica de análise temática, que consiste na classificação do texto em temas, sendo necessário identificar os núcleos de sentido que compõem a comunicação (Minayo, 1994). Essa técnica é dividida em três etapas: (1) pré-análise, (2) exploração do material e (3) tratamento e interpretação dos resultados. De acordo com Spink e Lima (2004), como é comum em pesquisas que buscam compreender os sentidos dos fenômenos sociais, "a análise inicia-se com uma imersão no conjunto de informações coletadas, procurando deixar aflorar os sentidos, sem encapsular os dados em categorias, classificações ou tematizações definidas a priori" (Spink, Lima, 2004, p. 106).

Isso não significa que as categorias e tematizações prévias não façam parte da análise, contudo, não são impositivas (Spink, Lima, 2004). Há, portanto, um diálogo possível entre os sentidos construídos durante a pesquisa e aqueles decorrentes da familiarização prévia com o campo (revisão bibliográfica) e teorias de referência. Dessa forma, as categorias não foram identificadas previamente, mas a partir da escuta e análise das transcrições das reuniões do grupo.

Para discutir os resultados, apresentamos o processo de análise do problema educativo, destacando os principais aspectos que influenciaram a negociação da equipe.

\section{Resultados e discussão}

Organizamos a narrativa do processo de pesquisa em função dos elementos constitutivos da análise do problema: definição do problema educativo, dos objetivos da intervenção e da teoria norteadora. Os integrantes da equipe foram representados por códigos, para garantir o anonimato, da seguinte forma: PTE (pesquisadora em tecnologia educacional); PVE (pesquisador em vídeo educativo); PPM (professora da disciplina de Psicologia Médica); PPT1 (professor-coordenador de Psicopatologia); PPT2 (professora de Psicopatologia). Selecionamos trechos ilustrativos dos diálogos, para fundamentar as questões discutidas, e grifamos os fragmentos considerados mais significativos para análise.

\section{Definição do problema educativo}

A proposta de desenvolvimento do Projeto Vivências teve início quando três professores das disciplinas Psicologia Médica e Psicopatologia, de um curso de Medicina, envolvidos em um grupo de pesquisa sobre medicina baseada em narrativas, procuraram a parceria de pesquisadores da área de Tecnologia Educacional em Saúde, com o objetivo de construir um site com depoimentos sobre experiências de adoecimento e tratamento de pacientes com transtornos mentais e doenças neoplásicas.

Os pesquisadores de $T E$, já no primeiro encontro, situaram o foco do trabalho no campo da pesquisa educacional. Os professores se interessaram em refletir sobre o problema educativo de suas áreas, questionando sobre como um material com depoimentos poderia contribuir para a formação médica.

PPM: “[...] tudo começou porque nós resolvemos fazer um site com experiências de adoecimento e tratamento [...] As experiências dos doentes estariam disponíveis, como um banco de dados, onde as pessoas falam (ou filmadas ou gravadas) e aí os alunos, os professores, podem usar desde exemplarmente, como também podem fazer pesquisa. Aí, a PTE criou o seguinte: 'não, mas eu quero mais. Eu quero que haja um espaço para formação, para o aprendizado da experiência'". 
DESENVOLVIMENTO DE UM AMBIENTE VIRTUAL ...

Nesse processo, desafios e oportunidades relacionados aos contextos da formação em saúde foram discutidos, aprofundando necessidades do ensino médico.

PPM: “[...] o problema é que todo o ensino médico, seja pelo problem-based, seja o método tradicional, o paciente, a experiência do paciente é um mero exemplar [...] a dimensão experiencial sempre fica de fora [...] fica no limbo".

Os questionamentos centraram-se, sobretudo, no desequilíbrio existente entre a abordagem técnica das patologias e a dimensão subjetiva envolvida no processo de adoecimento. Sem desconsiderar o papel do conhecimento técnico-científico na formação, ressaltaram a necessidade de se valorizarem as narrativas dos pacientes para se transformar e humanizar a relação médico-paciente.

\section{Definição dos objetivos do ambiente virtual}

A equipe de TE buscou articular os desafios do contexto educativo com as possibilidades de uso das TICs para enriquecer a experiência de aprendizagem e interação entre os alunos.

PTE: “[...] o eixo central é uma base de informações, de vídeos com entrevistas dos pacientes que ele pode acessar. Só que a nossa intenção não é só criar uma base de informação [...] a gente queria construir outras oportunidades de aprendizagem e interação [...] É isso que eu acho que é o nosso objetivo".

Definiu-se que o ambiente seria restrito a professores, alunos e pacientes envolvidos nas disciplinas de Psicologia Médica e Psicopatologia. Devido às especificidades de cada disciplina, definiu-se que o ambiente teria como foco tanto a experiência do paciente sobre o adoecimento e tratamento, quanto a do aluno que se depara com o desafio e responsabilidade de lidar com a vida humana.

PPT2: “[...] são as duas dimensões da experiência que no nosso trabalho a gente não pode deixar de fora: a experiência do aluno e do paciente".

Concluiu-se, então, que o ambiente teria como objetivo oferecer, aos estudantes, a possibilidade de entrarem em contato com experiências de pacientes no adoecimento e tratamento, por meio de uma diversidade de depoimentos em vídeo, áudio, texto e outros recursos da Web 2.0 (tais como blogs, wiki e comunidades), possibilitando, ainda, que as impressões sobre estas experiências fossem compartilhadas.

\section{Definição da teoria norteadora para pesquisa e desenvolvimento do ambiente}

Para definir a teoria norteadora, na medida em que as discussões apontavam questões pedagógicas críticas, a equipe de TE pesquisava o referencial teórico que pudesse fundamentar a análise do problema. Esse referencial era discutido nas reuniões e norteava buscas subsequentes. Foram identificados três principais momentos nesse processo de construção coletiva:

$1^{\circ}$ momento - discussão sobre a valorização da experiência e vivência do aluno

O ponto de partida foi a compreensão do aluno como centro do processo de ensino-aprendizagem, que constrói conhecimentos a partir da interação com o meio e com outros indivíduos. Esta discussão fez com que a equipe de TE buscasse um referencial sobre: aprendizagem experiencial, afetiva e situada.

PTE: “Do ponto de vista educacional, a maior contribuição desse projeto, em termos de inovação educacional, é que a gente sai do problem-based, que é a aprendizagem baseada em problema para a questão do experiential-based. Que o cara vai vivenciar, ele não vai estudar um caso e pegar um caso para distrinchar. Ele vai vivenciar o sofrimento afetivo...". 
$2^{\circ}$ momento - discussão sobre os princípios da aprendizagem experiencial, afetiva e situada (situated learning)

Essa discussão apontou a necessidade de se buscar um referencial que valorizasse a experiência na perspectiva do sujeito da ação.

PPT2: “[...] essa exposição pode se dar do ponto de vista do sujeito no aprendizado na perspectiva da terceira pessoa e não da primeira. $E$, na verdade, o que a gente estava querendo ressaltar era a exposição do aluno à experiência em si".

PPT1: "Você falou de situated... Situated e embodied, eu pensei agora.... Porque no campo de discussão da ciência cognitiva, o tipo de abordagem próxima ao que a gente tenta trazer para a Psicopatologia, tem sido chamada de embodied ou situated cognition".

PTE: "Eu vou procurar embodied também".

$3^{\circ}$ momento - discussão sobre aprendizagem corporificada (embodied learning)

A equipe de TE buscou um referencial teórico sobre: "aprendizagem corporificada" e identificou a aprendizagem situada e a corporificada como sendo as teorias norteadoras (Dall'alba, Bernacle, 2005; Billet, 1994).

PTE: “[...] quando você aprende embodied você tem uma transformação de você integral, não é só do compartimento intelectual. Você não constrói só um conhecimento, você constrói uma ética [...] O que eu achei muito adequado para essa questão que a gente está discutindo da problemática da relação médico-paciente [...] Da escuta, do entendimento do que é o sofrimento [...] Isso aqui foi uma direção fundamental, que de uma certa maneira isso não estava tão explícito... Hoje, a gente fala: "nós vamos trabalhar com embodied learning".

O construtivismo foi, portanto, a matriz teórica que orientou as opções da equipe na seleção da teoria norteadora para fundamentar o design e análise desta intervenção. A abordagem construtivista de aprendizagem considera que o conhecimento não é algo acabado e objetivo, mas construído pelo sujeito por meio de suas interações no mundo, mediadas por artefatos culturais (Rogoff, 2003; Cole, Wetsch, 1996). Essa filiação evidenciou-se, desde o primeiro momento, na fala da pesquisadora de TE sobre o papel dos alunos ao vivenciarem o processo de aprendizagem.

A aprendizagem situada compreende que o contexto é fundamental e indissociável da aprendizagem que nele se realiza, uma vez que tem o poder de interferir na postura e nas ações dos alunos, influenciando, de maneira significativa, a construção do conhecimento (Billett, 1994). A aprendizagem corporificada, por sua vez, considera que a cognição envolve, além dos aspectos cognitivos, os aspectos físicos, emocionais e afetivos (Dall'alba, Bernacle, 2005). Segundo Dall'alba e Bernacle (2005), tal reconhecimento favorece uma aprendizagem "corporificada", pois assume a indissociabilidade entre corpo e mente na aprendizagem.

Com base na análise da negociação da equipe sobre o problema educativo, foi possível identificar, de acordo com Jonassen (2000), Tardif (2002) e Olafson e Schraw (2006), as crenças epistemológicas e os saberes docentes dos pesquisadores que influenciaram este processo.

\section{Análise das crenças epistemológicas}

Em função dos campos de conhecimento dos pesquisadores envolvidos, as crenças epistemológicas que se destacaram na negociação da equipe foram as relacionadas à formação em saúde, saúde e tecnologia educacional. 
DESENVOLVIMENTO DE UM AMBIENTE VIRTUAL ...

\section{Crenças sobre formação em saúde}

Kang (2008) classifica as crenças dos professores sobre a formação a partir de um continuum cujas extremidades são: "centrado no aluno" e "centrado no professor". Na análise das falas, verificou-se que as crenças sobre formação médica foram "centradas no aluno", uma vez que foi valorizado, na aprendizagem, o papel ativo do aluno na construção do conhecimento (Kang, 2008).

\section{PTE: “Eu sinto que a vivência do aluno é que é mais importante que a experiência que você vai oferecer para ele [...]. Porque ele vive isso no cotidiano dele, ele vai para a enfermaria e vive isso... E a gente quer tentar potencializar e trazer essa vivência para dentro de um contexto".}

Os pesquisadores apresentaram crenças compatíveis com a aprendizagem corporificada, que pressupõe que não existe separação entre mente e corpo e, dessa forma, todas as dimensões do indivíduo (cognitiva, afetiva e ética) devem ser consideradas na aprendizagem (Dall'alba, Bernacle, 2005). Inclusive, no diálogo a seguir, destaca-se a convergência de crenças entre o professor (PPT1) e a pesquisadora de TE.

\section{PPT1: "tem uma cisão tradicionalmente estabelecida entre cognição e afeto... Para não parecer que a gente está do outro lado.}

PTE: Nós também temos, um preconceito em relação a isso. Porque a gente também entende que não existe saber sem sentir. Dentro de uma perspectiva construtivista essa separação é inexistente...".

Além disso, consideraram que, na formação médica, valorizar a experiência do adoecimento e tratamento do paciente possibilita a construção de um conhecimento sobre o sofrimento humano capaz de transformar a relação médico-paciente.

PPM: "O problema é dar lugar à experiência como um lugar de valor. E utilizar isso do ponto de vista pedagógico. Que como disse bem o PPT1. Não é que ela não exista no cenário pedagógico, ela até existe, mas ela é rapidamente substituída".

PTE: "Ela é vivenciada de uma outra maneira. Ela é terceirizada...".

PPM: "Gostei dessa classificação... Isso é coisa de paciente... A terceirização é isso. Os médicos e os alunos não precisam se preocupar... Ou melhor, não precisam se deixar afetar".

Nota-se que, nos dois trechos anteriores, os professores (PPT1 e PPM) apresentaram suas crenças sobre formação em saúde, fazendo uma crítica ao ensino tradicional - que fragmenta afeto e cognição e desvaloriza a experiência do paciente. Essa discussão indica uma compreensão de que a formação deve preparar os profissionais para estabelecerem uma relação humanizada na prática médica, não reduzindo o paciente a órgãos e sistemas, mas o compreendendo como um sujeito em sua totalidade (Sucupira, 2007). Nas discussões da equipe, verificou-se que essa crença ancorou a definição do problema educativo.

\section{Crenças sobre saúde}

A equipe pautou-se no conceito amplo de saúde, em que esta não é considerada ausência de doença, mas inclui as esferas biológica, histórica, sociológica e tecnológica (Amancio Filho, 2004). Isso fica claro nos argumentos dos pesquisadores sobre a importância de o médico considerar a narrativa dos pacientes como um aspecto do cuidado em saúde. Essa é uma crença que reforça a compreensão do paciente como o "centro e o objeto da atenção", considerado em todas as suas dimensões (Sucupira, 
2007, p.626). Os pesquisadores também questionaram os valores éticos dos serviços de saúde e da formação, em que há diferenças no cuidado de acordo com a classe social.

PPM: "[...] O ensino médico da universidade, por exemplo, qual é a moldura que nós temos que ter no sentido de fazer limites do que é aceitável? [...] O aluno só faz determinadas coisas, porque sabe que pode fazer. Agora, quando [...] acabam a residência e vão trabalhar na rede privada, lá ouvem todos os pacientes. Por que? Porque é um valor de mercado. Vai não ouvir na rede privada para você ver".

PPT1: "Mas o valor não é ouvir o paciente, o valor é sua posição no mercado".

PPM: "Então, é esse o valor que vai nos reger? É o valor do mercado? [...]".

PVE: "Mesmo na rede privada? Será que realmente escuta o paciente?".

PPM: "[...] Mas escuta muito mais, porque a rede privada é infiltrada pela universidade, e eu fiquei 11 dias internada e fiquei impressionada, porque eu vi [...] a força dos protocolos, da rotina, da burocracia [...] Agora ali no HU se permite umas tantas coisas".

PTE: "Como se não pagasse caro por aquilo, imposto...".

Os questionamentos evidenciaram crenças de saúde baseadas nos princípios de integralidade da assistência e de equidade no acesso aos serviços de saúde. Esses princípios foram compartilhados por todos os participantes, como evidenciado nos diálogos, em que a participação dos pesquisadores de TE (PVE e PTE) reforçou os argumentos dos professores (PPM e PPT1). Indicam, portanto, convergência nas crenças sobre saúde e prestação de serviço à saúde.

\section{Crenças sobre tecnologia educacional}

A equipe se posicionou criticamente em relação à tecnologia, questionando sua contribuição à formação. Os pesquisadores demonstraram uma compreensão de que a tecnologia deve ser apropriada pelos sujeitos, integrando valores substantivos aos contextos de ensino-aprendizagem, como: colaboração, ética e inserção social.

PPT1: “[...] estávamos falando da questão dos valores. Como se transmite valor? A gente transmite conhecimento, unidade cognitiva e valores a gente pouco transmite. Esse tipo de instrumento pode ser uma maneira de transmitir valor".

PPT1: "Inclusive para a clientela que nos procura, essas coisas são meio extraordinárias também. Acesso a internet... Acho que tem esse ganho também".

PTE: "Tem um ganho social enorme [...] Com esse caráter mesmo, terapêutico".

Essas reflexões apontaram crenças compatíveis com a Teoria Crítica da Tecnologia - TCT (Feenberg, 2003), que pressupõe que a tecnologia não é neutra. Isto significa que, ao se incluir a tecnologia, não se está adicionando apenas novos métodos aos processos de aprendizagem, mas também novos valores. Contudo, a TCT não considera que esses valores são impostos, mas definidos pelos sujeitos ao se apropriarem da tecnologia.

PTE: “A gente tem que buscar formas de que os alunos tenham outra função [...] Que instrumentos a web pode oferecer para que a gente parta do aluno? Da experiência do aluno, da experiência do paciente". 
Verificou-se uma convergência de crenças, entre os pesquisadores das duas áreas, no sentido de compreenderem a tecnologia como uma ferramenta para a autonomia de alunos e pacientes e transformação da formação médica.

\section{Análise dos saberes docentes}

Foram analisados os saberes docentes experienciais (construídos na prática pedagógica) e disciplinares (construídos na formação), discutindo-se como estes foram integrados na análise do problema.

\section{Saberes experienciais}

Para a análise do problema educativo, Mion e Angotti (2005) consideram relevante aprofundar a discussão sobre a prática educativa e a situação social em que esta se realiza, as mudanças desejáveis e os caminhos para transformar essa prática. Os saberes experienciais dos professores ofereceram uma compreensão sobre as questões vivenciadas no contexto da formação e do serviço em saúde, apontando desafios e oportunidades para caracterizar o problema educativo do ponto de vista da prática. A professora PPM relatou os desafios enfrentados pelos alunos ao se depararem com o sofrimento do paciente.

PPM: "Qual é o barato do $M 6^{4}$ ? [...] ele está no vão central da ponte Rio-Niterói. Ele está no meio do paciente e do médico. Ele está no meio do caminho diante de toda aquela ventania. Ele vive um drama de pela primeira vez atender um paciente. E o paciente tem o drama dele. É desse encontro de dramas que saem as histórias mais ricas...".

A professora PPT2, ao narrar a participação dos pacientes na disciplina, refletiu sobre o papel que lhes atribui em suas atividades de ensino. Assim, as discussões sobre as práticas dos professores possibilitaram compreender as estratégias adotadas para enfrentar o problema educativo.

\section{PPT2: "Os pacientes contam para os alunos o que é a experiência de ter um problema psiquiátrico. Com temáticas que eles escolheram (eles os pacientes). Então, eles escolhem as temáticas e contam para os alunos o que é isso".}

PTE: “Vocês não têm nenhuma ingerência sobre o que o paciente vai falar?".

PPT2: "Nenhuma. Mas por outro lado... Obviamente, esses pacientes que estão trabalhando comigo há dois anos, não são mais os mesmos pacientes...".

A partir destes relatos, identificou-se que, mesmo compartilhando abordagens comuns, os professores envolvidos neste projeto problematizaram diferentes experiências marcadas pelos contextos em que se desenvolvem suas disciplinas. A fala da professora de Psicologia Médica voltou-se para a vivência do aluno diante do sofrimento do paciente no leito hospitalar (doenças neoplásicas). Já, a professora de Psicopatologia, concentrou-se na experiência do paciente - pautada pelo atendimento ambulatorial - e no papel ativo que ele desempenha na definição e condução de questões que considera importantes sobre seu adoecimento e tratamento.

\author{
${ }^{6} \mathrm{OM}$ ( é o $6^{\circ}$ período \\ da Faculdade de \\ Medicina, quando os \\ alunos entram em \\ contato, pela primeira \\ vez, com pacientes \\ internados, como parte \\ integrante da equipe de \\ saúde.
}


Com base nessas especificidades, os pesquisadores de TE contribuíram com saberes experienciais sobre educação e tecnologia educacional, aliando as necessidades dos contextos com as características e potencialidades das TICs.

PTE: “[...] vamos pensar na realidade: vocês dão aula, de tanto em tanto tempo, para um grupo $x$ de alunos, vocês dividem a turma em três, trazem os pacientes, os pacientes apresentam o seu depoimento. Os alunos perguntam para ele? [...] o que eu estou fazendo é vendo as situações que eles já vivenciam. Não que a tecnologia vá substituir, mas que pode enriquecer...".

PPM: "O problema é que eu não dou aula com pacientes, eles estão nas enfermarias. [...] os alunos falam sobre seus pacientes da enfermaria [...]".

PTE: “Então, o aluno pode ter espaço de voz também... Ele trazer os casos, as vivências".

PPT1: "Acho que é isso, a gente pode incluir a experiência do aluno".

O diálogo revelou como a proposta de uso das TICs foi sendo construída de acordo com as necessidades dos professores apontadas durante as discussões. A integração dos saberes experienciais de ambos os campos foi crucial para análise do problema educativo e uso das TICs como um dos possíveis caminhos para mudar a prática.

\section{Saberes disciplinares}

Enquanto os pesquisadores de TE contribuíram com conceitos relacionados à educação e ao uso de TICS, os pesquisadores da saúde contribuíram com aqueles referentes à relação com os pacientes. $\mathrm{O}$ foco principal da discussão foi o conceito de "experiência", com base na perspectiva de ambas as áreas.

A pesquisadora de TE discutiu o conceito de experiência, contrapondo com a abordagem da aprendizagem baseada em problemas.

PTE: "No problem-based a gente coloca o aluno no centro do processo, o aluno está diante de um problema, mas ele está todo organizado [...] A diferença da experiência que eles vivenciam na Psiquiatria é exatamente essa: trazem o paciente para falar o que o paciente sente. E não para ter um estudo de caso [...] É isso que eu acho que é inédito".

A pesquisadora fez o contraponto entre as duas abordagens, porque ambas têm como pressuposto a experiência ativa do aluno no processo de ensino-aprendizagem, já que, na aprendizagem baseada em problemas (ABP), os alunos resolvem problemas e refletem sobre suas experiências (Hmelo-Silver, 2004). Na sua fala, a pesquisadora reconheceu o valor da experiência na ABP e apontou a necessidade de se buscar uma abordagem que fundamentasse a valorização da experiência do aluno, não só cognitiva, mas, também, afetiva, ao entrar em contato direto com o sofrimento do paciente.

Os professores analisaram o conceito de experiência com base na perspectiva dos pacientes.

PPT1: "Você pode falar da experiência de fora [...] tem artigos que tratam da experiência e que valorizam a perspectiva da primeira e da segunda pessoa, ou seja, trata disso a partir de relato, valoriza os relatos. O relato de quem ouve vozes é uma peça fundamental ou não. Ou simplesmente você pode dizer 'pessoas ouvem vozes e eu falo dessa experiência na terceira pessoa'".

PPT1: “[...] tem essa perspectiva mais fenomenológica e corporificada [...] que se chama teoria da interação. Que isso é dado de forma imediata no próprio sentido...

Intermodalidade sensorial se dá na relação intercorporal que você pode ter acesso, o que 
não significa que sinta o que o outro sente, mas pela sua perspectiva de ser dotado de consciência e corporificado... Acho que a questão da corporificação [...] a gente pode tomar como central também aqui".

Os professores se basearam nos conceitos de "primeira pessoa" e "corporificação" para caracterizar a experiência do paciente, em sua dimensão subjetiva. Para eles, o relato do paciente é uma questãochave para proporcionar uma aprendizagem que possibilite ao aluno compreender o adoecimento e o tratamento, a partir de suas próprias vivências. O conceito de corporificação, discutido pelo PPT1, e adotado em sua linha de pesquisa, foi fundamental na seleção da aprendizagem corporificada, identificada como a fundamentação teórica do problema educativo e do desenvolvimento do ambiente.

Essa discussão conceitual permitiu compreender o problema educativo, com base em diferentes perspectivas, e definir a teoria norteadora do projeto.

\section{Considerações finais}

O objetivo deste trabalho foi investigar a fase inicial de análise do problema educativo, da pesquisa e desenvolvimento de um ambiente virtual para ensino de Medicina, apoiado na Pesquisa Baseada em Design (DBRC, 2003); e analisar os principais aspectos que influenciaram no processo de negociação da equipe.

O problema educativo discutido foi o modelo tradicional da formação médica e a necessidade de se criarem oportunidades pedagógicas que valorizem a experiência subjetiva dos pacientes como um caminho para transformar a relação médico-paciente. A análise desse problema não foi organizada em divisões de tarefas, como é comum em projetos com o uso das TICs, em que os professores contribuem com o conteúdo e, a equipe de TE, com o modelo pedagógico. A dinâmica fundada na parceria possibilitou negociar e construir uma compreensão integrada do problema, do ponto de vista teórico-prático. Os principais aspectos que influenciaram esta atividade foram as crenças epistemológicas (Jonassen, 2000) e saberes docentes (Olafson, Schraw, 2006; Tardif, 2002) dos pesquisadores.

Os pesquisadores manifestaram crenças sobre saúde, formação em saúde, e tecnologia educacional. Em relação à saúde, assumiram um conceito amplo, atribuindo papel central aos pacientes e às suas experiências subjetivas na tomada de decisão do profissional. No que diz respeito à formação em saúde, apontaram a necessidade de a formação médica investir não apenas no ensino técnico-científico mas, também, na transmissão de valores humanísticos aos alunos. Com base em crenças compatíveis com a aprendizagem corporificada, a equipe compreendeu que, ao entrarem em contato direto com a experiência subjetiva dos pacientes, os alunos mobilizam aspectos cognitivos, afetivos e éticos, que permitem a compreensão aprofundada sobre o adoecimento e tratamento, a partir de suas próprias vivências. $\mathrm{O}$ ambiente virtual foi compreendido como um meio de potencializar o ensino, conferindo cooperação, interação, autonomia ao processo de ensino-aprendizagem.

Pôde-se observar que, neste estudo, as crenças dos pesquisadores foram convergentes, delineando um processo equilibrado de negociação. Esta característica contribuiu para o desenvolvimento de um trabalho marcado pelo consenso, facilitando a compreensão do problema e a construção da identidade coletiva indispensável para o trabalho em equipe em projetos dessa natureza (Fazenda, 1995). Essa convergência foi uma característica peculiar deste grupo, porém, isto nem sempre ocorre em trabalhos em equipe, tornando-se necessário o enfrentamento dos conflitos para se viabilizar um projeto comum (Pinho, 2006).

Destacou-se, também, a integração dos saberes experienciais e disciplinares, possibilitando a articulação de diferentes perspectivas na análise do problema. Como os sujeitos da equipe possuem diferentes expertises e, portanto, relações diferenciadas com o campo do ensino médico, o compartilhamento de saberes permitiu que a análise incluísse diferentes dimensões do problema, relacionadas: às práticas na formação e no serviço de saúde; às estratégias pedagógicas adotadas nas disciplinas; às potencialidades das TICs para solucionar o problema, e aos conceitos teóricos sobre 
educação, saúde e relação médico-paciente. Os diferentes saberes teóricos e práticos se complementaram, configurando, assim, um trabalho interdisciplinar (Winters, Mor, 2008). Em relação aos saberes disciplinares, isso ficou claro na definição da teoria norteadora, em que a equipe de TE não impôs um modelo predefinido. A aprendizagem corporificada não era conhecida pelos participantes e foi selecionada por ser adequada ao projeto e compatível com a abordagem narrada pelos professores da área médica sobre suas pesquisas e práticas. Em relação aos saberes experienciais, o trabalho interdisciplinar se destacou nos objetivos do ambiente virtual, já que estes foram definidos a partir da integração dos conhecimentos sobre o uso pedagógico das TICs e aqueles relacionados ao contexto das disciplinas, incluindo as diferentes estratégias utilizadas pelos professores: valorizar o papel ativo dos pacientes psiquiátricos na interação com os alunos e valorizar a reflexão dos alunos sobre suas experiências diante de pacientes com doenças neoplásicas no leito hospitalar.

Outro aspecto que se destacou foi o papel da pesquisadora de $T E$, que orientou as discussões e organizou o trabalho em equipe. A pesquisadora buscou escutar os participantes, sintetizando saberes, problematizando o ensino e propondo caminhos compatíveis com as necessidades pedagógicas do contexto. Barab et al. (2005) consideram que essa postura colaborativa do pesquisador de TE, privilegiando a escuta e a compreensão do problema educativo, é indispensável para se construírem intervenções ancoradas nas necessidades sentidas na prática.

Concluiu-se, portanto, que, na análise de problemas complexos, como os da saúde, a parceria é essencial para o desenvolvimento de intervenções pedagógicas inovadoras. Isso porque os sujeitos envolvidos na prática educativa, especificamente os professores, vivenciam o contexto da formação, podendo, portanto, problematizá-lo. Por outro lado, os pesquisadores de TE contribuem para instigar a reflexão sobre ensino e aprendizagem e sugerir possibilidades de intervenção adequadas às necessidades do contexto educacional. Com isso, quanto mais o problema educativo for compreendido em sua complexidade, maiores as possibilidades de superá-lo (Mion, Angotti, 2005).

Trabalhos desta natureza podem contribuir para o campo das Tecnologias de Informação e Comunicação no Ensino da Saúde, já que assumem a singularidade das intervenções pedagógicas. $O$ ensino tecnicista da saúde, a necessidade de se investir na humanização do cuidado e de se valorizar a dimensão subjetiva do adoecimento são questões bastante discutidas na literatura (Sucupira, 2007; Amâncio Filho, 2004; Ceccim, Feuerwerker, 2004). Contudo, com a análise do problema, essas questões foram compreendidas em suas especificidades, incluindo as situações e práticas específicas nas quais estes professores estavam envolvidos, assim como suas crenças e saberes.

Nesse sentido, a pesquisa no campo de ensino da saúde, orientada pela PBD, possibilita desenvolver intervenções relevantes para o contexto de ensino e, também, construir conhecimentos sobre o próprio processo de desenvolvimento.

\section{Colaboradores}

Paula Ramos responsabilizou-se pela escrita do artigo, parte de sua pesquisa de tese de doutorado. Miriam Struchiner, orientadora da tese e coordenadora da pesquisa na qual se insere este estudo, responsabilizou-se pela orientação do artigo. 
DESENVOLVIMENTO DE UM AMBIENTE VIRTUAL ...

\section{Referências}

AMANCIO FILHO, A. Dilemas e desafios da formação profissional em saúde. Interface - Comunic., Saude, Educ., v.8, n.15, p.375-80, 2004.

ANGULO, J.F. Investigación-acción y curriculum: una nueva perspectiva en la investigación educativa. Invest. Esc., n.11, p.39-49, 1990.

BARAB, S. et al. Making learning fun: Quest Atlantis, a game without guns. ET\&R, v.53, n.1, p.86-107, 2005.

BARDIN, L. Análise de conteúdo. Lisboa: Edições 70, 1977.

BILLET, S. Situated learning: a workplace experience. Aust. J. Adult Educ., v.34, n.2, p.112-30, 1994.

BROWN, A.L. Design experiments: theoretical and methodological challenges in creating complex interventions. J. Learn. Sci., v.2, n.2, p.137-78, 1992.

CECCIM, R.B.; FEUERWERKER, L.C.M. Mudança na graduação das profissões de saúde sob o eixo da integralidade. Cad. Saude Publica, v.20, n.5, p.1400-10, 2004.

COLE, M.; WERSCHT, J.V. Beyond the individual-social antimony in discussions of Piaget and Vygotsky. Hum. Dev., v.39, n.3, p.250-6, 1996.

COLLINS, A. Towards a design science of education. In: SCANLON. E.; O'SHEA, T. (Eds.). New directions in educational technology. Berlim: Springer, 1992. p.15-22.

DALL'ALBA, G.; BARNACLE, R. Embodied knowing in online environments. Educ. Philos. Theory, v.37, n.5, p.119-44, 2005

DESIGN-BASED RESEARCH COLLECTIVE. DBRC. Design-Based research: an emerging paradigm for educational inquiry. Educ. Res., v.32, n.1, p.5-8, 2003.

EDELSON, D.C. Design research: what we learn when we engage in design. J. Learn. Sci., v.11, n.1, p.105-121, 2002.

FAZENDA, I.C. Interdisciplinaridade: história, teoria e pesquisa. 2.ed. Campinas: Papirus, 1995.

FEENBERG, A. O que é a Filosofia da Tecnologia. Aula Virtual Democ., v.5, n.1, 2004. Disponível em: <http://www.rohan.sdsu.edu/faculty/feenberg/oquee.htm>. Acesso em: 23 mar. 2009.

GREENHALGH, T. Is my practice evidence-based? Bri. Med. J., v.313, p.957-8, 1996.

HMELO-SILVER, C.E. Problem-based learning: what and how do students learn? Educ. Psychol. Rev., v.16, n.3, p.235-66, 2004.

HUNTER, K.M.; CHARON, R; COULEHAN, J.L. The study of literature in medical education. Academic Med., v.70, n.9, p.787-94, 1995.

JONASSEN, D.H. Toward a design theory of problem solving. ETD\&R, v.45, n.4, p.63-85, 2000.

. Instructional design models for well-structures and ill-structures problemsolving learning outcomes. ETR\&D, v.45, n.1, p.65-94, 1997.

JUUTI, K.; LAVONEN, J. Design-based research in science education: one step towards methodology. Nordina, v.4, p.54-68, 2006.

KANG, N.H. Learning to teach science: personal epistemologies, teaching, goals and practices of teaching. Teach. Teach. Educ., v.24, n.2, p.478-98, 2008.

KOZMA, R. Reflections on the state of educational technology research and development. ETD\&R, v.48, n.1, p.5-15, 2000. 
MINAYO, M.C. O desafio do conhecimento: pesquisa qualitativa em saúde. São Paulo: Hucitec, 1994.

MION, R.A.; ANGOTTI, J.A.P. Em busca de um perfil epistemológico para a prática educacional em Educação em Ciências. Cienc. Educ., v.11, n.2, p.165-80, 2005.

OLAFSON, L.; SCHRAW, G. Teachers beliefs and practices within and across domains. Int. J. Educ. Res., v.45, n.1, p.71-84, 2006.

PINHO, M.C. Trabalho em equipe de saúde: limites e possibilidades de atuação eficaz. Cienc. Cognição, v.3, n.8, p.68-87, 2006.

PRIMO, A. O aspecto relacional das interações na Web 2.0. E-Compós, v.9, p.1-21, 2007.

RAMOS, P. Ambiente virtual vivências: análise do processo de desenvolvimento na perspectiva da pesquisa baseada em design. 2010. Tese (Doutorado em Educação em Ciências e Saúde) - Núcleo de Tecnologia Educacional para a Saúde, Universidade Federal do Rio de Janeiro, Rio de Janeiro. 2010.

REEVES, T.C.; HERRINGTON, J.; OLIVER, R. Design research: a socially responsible approach to instructional technology research in higher education. J. Comput. Higher Educ., v.16, n.2, p.96-116, 2005.

ROGOFF, B. The cultural nature of development. Oxford: University Press, 2003.

SERPA JR., O.D. Clínica e evidência: em que se baseiam as nossas decisões? Cad. IPUB, v.15, p.61-79, 1999.

SPINK, M.J.; LIMA, H. Rigor e visibilidade: a explicitação dos passos da interpretação. In: SPINK, M.J (Org.). Práticas discursivas e produção de sentido no cotidiano: aproximações teóricas e metodológicas. 2.ed. São Paulo: Cortez, 2000. p.93-122.

STRUCHINER, M. Projeto Vivências: espaços virtuais na aprendizagem das dimensões experiencial e narrativa dos processos de adoecimento. Rio de Janeiro, 2008. Projeto de pesquisa submetido à Faperj.

SUCUPIRA, A.C. A importância do ensino da relação médico-paciente e das habilidades de comunicação na formação do profissional de saúde. Interface - Comunic., Saude, Educ., v.11, n.23, p.619-35, 2007.

TARDIF, M. Saberes docentes e formação profissional. Petrópolis: Vozes, 2002.

VAN DEN AKKER, J. Principles and methods of development research. In: VAN DEN AKKER, J. et al. (Eds.). The design methodology and developmental research in education and training. Netherlands: Kluwer Academic Publishers, 1999. p.1-14.

WANG, F.; HANNAFIN, M.J. Design-based research and technology-enhanced learning environments. ETR\&D, v.53, n.4, p.5-23, 2005.

WINTERS, N.; MOR, Y. IDR: a participatory methodology for interdisciplinary design in technology enhanced learning. Comput. Educ., v.50, n.2, p.579-600, 2008. 
RAMOS, P. STRUCHINER, M. Desarrollo de un ambiente virtual para la enseñanza de la medicina por un equipo multi-disciplinario: factores que influyen en el análisis del problema educativo. Interface - Comunic., Saude, Educ., v.15, n.36, p.227-42, jan./mar. 2011.

Este estudio investiga la fase de análisis del problema educativo en el proceso de investigación y desarrollo de un ambiente virtual para la enseñanza de Medicina apoyado en la metodología de la Investigación Basada en Design. El equipo multidisciplinario, compuesto por investigadores de tecnología educacional y salud, discutió el problema de la formación tecnicista y la necesidad de enfatizar experiencias subjetivas de los pacientes como forma de incluir valores éticos en la formación. Con base en el análisis de contenido de las transcripciones de las reuniones de equipo, se discuten los aspectos que influyen en la negociación para definición del problema educativo, de los objetivos del ambiente y de la teoría norteadora de su desarrollo. Se concluye que, en el análisis de problemas complejos como los de la salud es fundamental la integración de las creencias epistemológicas, y de los saberes docentes.

Palabras clave: Investigación basada en design. Ambiente virtual de aprendizaje. Formación médica. Creencias epistemológicas. Saberes docentes. 